\title{
About the Criteria for the Choice of Materials to Protect Against the Mechanical Dynamic Loading
}

\author{
V. Ya. Shevchenko ${ }^{a}$ *, A. S. Oryshchenko ${ }^{b}$, S. N. Perevislov ${ }^{a}$, and M. V. Sil'nikov ${ }^{c}$ \\ ${ }^{a}$ Grebenshchikov Institute of Silicate Chemistry, Russian Academy of Sciences, St. Petersburg, 199034 Russia \\ ${ }^{b}$ National Research Centre “Kurchatov Institute, Gorynin Central Research Institute of Structural Materials "Prometey," \\ St. Petersburg, 191015 Russia \\ ${ }^{c}$ Institute of Military-Technical Training and Security, Peter the Great St. Petersburg Polytechnic University, \\ St. Petersburg, 195251 Russia \\ *e-mail: Shevchenko@isc.nw.ru
}

Received December 3, 2020; revised January 26, 2021; accepted February 5, 2021

\begin{abstract}
A criterion for the selection of materials to protect against the mechanical dynamic loading is proposed and substantiated. The mechanisms of the fracture of brittle ceramic materials that are widely used in structures that prevent penetration and are very common in practice are discussed. Unlike other estimates, the proposed formula is based on the physical principle of comparing the total energies of loading and obstacles, and is in good agreement with the experimental data.
\end{abstract}

Keywords: barrier, elastic properties, ceramics, penetration depth

DOI: $10.1134 / \mathrm{S} 1087659621040179$

\section{INTRODUCTION}

The criterion is understood to mean the ability of the material to absorb, dissipate, and transform the loading energy. For example, for a projectile with a diameter (caliber) of $12.7 \mathrm{~mm}$, this energy is $\sim 17 \mathrm{~kJ}$ (at a loading rate of about $900 \mathrm{~m} / \mathrm{s}$ and an indenter mass of $46 \mathrm{~g})$.

M. Ashby published the classic work "Selection of materials for the design of technical applications" [1] in 1993 and introduced $M$ (the material index M), which in a semiquantitative form allows us to evaluate materials for security applications, where $E$ is Young's modulus, $\rho$ is density, and $C_{1}$ is the longitudinal speed of sound in matter.

$$
M=\frac{E^{\frac{1}{2}}}{\rho}=\frac{C_{1}}{\rho^{\frac{1}{2}}},
$$

This index is valid (according to Ashby) under conditions of quasi-static loading. At high loading rates, the entire amount of loading energy is distributed over a short period of time throughout the entire volume of the material. To prevent the destruction of the material (structure) and exclude penetration, this energy must be absorbed due to elastic and inelastic deformations, the mechanism of destruction, phase transitions, chemical reactions, and other mechanisms.

\section{ANALYTICAL PART}

Let us consider the process of interaction between the projectile and the obstacle sequentially.

For most ceramics, the elastic wave resulting from a high-velocity impact consists of surface waves (Rayleigh waves), shear waves ( $S$-waves), and compression waves ( $P$-waves). The wave energy of loading is roughly divided in the following ratio: Rayleigh wave, $67 \% ; S$-wave, $26 \%$; and compression wave $(P$ wave), $7 \%$ [2].

The overall picture of impact is very complex and involves several processes.

At average speeds $\left(v_{\mathrm{sp}} \ll C_{1}\right)$ the material of the striker undergoes deceleration due to destruction (dwell), the material of the barrier is destroyed due to the Hertz formation of radial and circular cracks, as well as the formation of Mescal zones and grinding of ceramics in them. In these zones, the plasticity of ceramics (or quasi-plasticity) plays an important role. The table from [2] presents estimates of the energy consumption of an impact on a ceramic barrier in combination with a substrate (two-layer) ${ }^{1}$. All stages indicated in the table are related to the elastic properties of the barrier. The term quasi-plasticity was analyzed in [3] and the term brittleness index, which is defined as the magnitude of the shear stress for the

\footnotetext{
${ }^{1}$ This term was introduced by V.Ya. Shevchenko in 1981. In the English-language literature, this design is called "Tandem."
} 
Table 1. Impact energy distribution [1]

\begin{tabular}{l|c|c|c|c|c}
\hline Platinum thickness & $\begin{array}{c}\text { Impact (elastic } \\
\text { energy absorption) }\end{array}$ & $\begin{array}{c}\text { Dwell (destruction } \\
\text { of the drummer) }\end{array}$ & $\begin{array}{c}\text { Spalling Hertzian } \\
\text { destruction } \\
\text { (Mescal zones) }\end{array}$ & $\begin{array}{c}\text { Spalling shredding } \\
\text { obstacle (Mescal } \\
\text { zones) }\end{array}$ & $\begin{array}{c}\text { Substrate stiffness } \\
\text { (substrate } \\
\text { absorption energy) }\end{array}$ \\
\hline Thin & 10 & 40 & 25 & 5 & 20 \\
Thick & 10 & 30 & 35 & 20 & 5 \\
\hline
\end{tabular}

onset of brittle fracture with the formation of cracks, was introduced (Table 1).

Quasi-plasticity can be defined as "all elastic deformations before the catastrophic failure of microcracks" [4] arising from various mechanisms-nano and micro-i.e., twinning, dislocations, grain boundaries, depreciation, microcracks, chips, phase transitions, micromelting, and dissociation.

The distribution of energy in a two-layer ceramic and aluminum by projectile of small diameter shows that the energy consumption of the projectile for the destruction of ceramics is insignificant $(2-10 \%)$. The main mechanism of energy dissipation is the plastic deformation of the substrate (20-40\%) and the impactor (10-15\% dwell), as well as the fracture energy of ceramics due to the formation of spalling $(40-70 \%)$ [5].

The term spalling refers to the grinding of a material from one particle size to a smaller particle size by breaking, crushing, cutting, vibratory grinding, and other processes. This phenomenon on impact is typical for fragile bodies.

Upon impact, a destruction region forms in front of the striker and remains in the conoidal destruction zone. This zone is called the Mescall zone. Mescall was the first to describe this phenomenon under supersonic impact, but it is also observed for normal loading rates.

When a striker strikes a brittle body, the fracture's conoid, radial cracks, and circular cracks are formed [6]. Such a cone is called a Hertzian cone.

For corundum, it was determined that, on average, one radial crack corresponds to a fraction of $\sim 150 \mathrm{MPa}$ of the developing hoop stress. The number of large radial cracks is also dependent and reflects the bending points that appear in a brittle body. They form as some kind of concentric circles around the impact site and appear after the radial cracks, but they have a common nature. The geometry of the sample significantly affects the process of destruction of the target and, under appropriate conditions, can lead to the complete erosion of the projectile (Dwell).

According to [7], it was found that the cone angle increases with an increase in Poisson's ratio for large diameter strikers and thus has a higher ballistic efficiency. When Poisson's ratio changes from 0.1 to 0.3 , the angle changes from $60^{\circ}$ to $70^{\circ}$. However, other fac- tors such as the projectile speed, substrate design, and stiffness also affect the taper angle of the failure.

The base of the Hertz cone is approximately half the projectile diameter plus twice the plate thickness [8].

Two stages of fracture exist in a material subjected to dynamic loading at high loading rates $\left(v_{\mathrm{sp}} \geq C_{1}\right)$. At the second stage, when the values of the loading speed become of the order of the longitudinal speed of sound (different for different types of materials), the effects related to the distribution of shock waves prevail. A decrease in the loading rate leads to destruction due to inertial effects, and the adiabatic response of the obstacle leads to melting. At this stage, an increase in the loading energy often leads to melting or evaporation of part of the barrier. For ceramics at loading rates suitable for the corresponding barriers, the response to an elastic wave is the governing process. In the elastic mode, the pressure arising in the compression wave is linearly proportional to the velocity of the material particle, the constant of proportionality is known as the elastic impedance equal to the product of the density and the velocity of the shock wave, and the velocity of the particle is equal to the velocity of the contact surface. The ratio of the target thickness to the projectile thickness is the factor determining the superposition of the compression and rarefaction waves. The dependence of the compression of real bodies on the pressure during compression by impact is determined by the Hugoniot function and characterizes the material on the stress-strain curve as the Hugoniot elastic limit (HEL), at which the material begins to transform into irreversible shear.

In ceramics, the HEL is much higher than the crushing strength, which tends to zero as the pressure of the compression pulse approaches the HEL. In general, the HEL can be expressed as $\Delta_{\mathrm{HEL}}=(1-v) Y_{\mathrm{c}} /(1-2 v)$, where $Y_{\mathrm{c}}$ is the compressive strength under uniaxial compression and $v$ is Poisson's ratio. This is analogous to the static loading of ceramics, which have very high compressive strength and very weak tensile strength.

Thus, the factors influencing the energy dissipation in the target are the elastic impedance and HEL. Other factors are the density, modulus of elasticity, and static compressive strength or hardness.

However, all these quantities are related by simple relations with dynamic properties [9]. 
The quantities $E, G, v$, and $K$ are related by the ratios

$$
\begin{aligned}
& G=E / 2(1+v), \\
& K=E / 3(1-2 v) .
\end{aligned}
$$

In turn,

$$
v=\frac{1-2\left(\frac{C_{\mathrm{t}}}{C_{1}}\right)^{2}}{2-2\left(\frac{C_{\mathrm{t}}}{C_{1}}\right)^{2}}, \quad E=\frac{C_{1}^{2} \rho[(1+v)(1-2 v)]}{(1-v)}, G=C_{\mathrm{t}}^{2} \rho .
$$

where $E, G, v$, and $K$ are Young's modulus, the shear modulus, Poisson's ratio, and the bulk modulus, respectively, and $C_{1}$ is the longitudinal speed of sound, $C_{\mathrm{t}}$ is the transverse speed of sound, and usually in isotropic solids the formula $C_{1} \approx \sqrt{2} C_{\mathrm{t}}$. It also for a shear wave that

$$
\begin{gathered}
C_{1}=\sqrt{\left.\frac{E(1-v)}{\rho(1+v)(1-2 v)}=\sqrt{(K+}+\frac{4}{3 G}\right) / \rho,} \\
C_{\mathrm{t}}=\sqrt{\frac{E}{2 \rho(1+\nu)}}=\sqrt{\frac{G}{\rho}} .
\end{gathered}
$$

All elastic constants in a solid are determined mainly by the velocities of the longitudinal and transverse sound waves, and are interrelated. Compression shockwaves ultimately bounce off the back surface as extensional waves. This dampens the compression waves in the material. The interference of compression and extension waves enhances the stretching at the appropriate locations of the barrier and leads to a fracture (delamination). This phenomenon is called spalling. ${ }^{2}$

When a wave travels through a high impedance plate that is coupled to a low impedance plate, tensile waves are emitted from the interface. This leads to structural failure if the high impedance plate is brittle. In the opposite case, if the wave initially passes through a low impedance plate coupled to a high impedance plate, then the compression waves are obviously reflected from the interface. This can be useful if we want to suppress a fracture in a brittle material such as ceramics.

The substrate material must withstand large plastic deformations before the fracture. The impact impedance $Z$ of the material is defined as

$$
Z=p_{0} U_{\mathrm{s}} \text {, }
$$

where $p_{0}$ is the density and $U_{\mathrm{s}}$ is the velocity of the shock wave and is quite similar to the elastic impedance

$$
Z=p C_{0},
$$

where $C_{0}$ is the volumetric speed of sound in the material. For the case when elastic waves propagate with the longitudinal speed of sound, then $C_{1}$ is used. The elastic impedance will be equal to

\footnotetext{
${ }^{2}$ See above.
}

$$
Z=p_{0} C_{1} \text {. }
$$

During the first stage of penetration, $0-9 \mu / \mathrm{s}$, cracks are formed near the ceramic-substrate interface due to the shear stresses of the substrate and begin to expand in the direction of motion of the projectile. Between 9 and $15 \mu / \mathrm{s}$, the impactor degrades, and the ceramic breaks down due to multitude of cracks that intersect and join. Approximately $40 \%$ of the projectile mass and energy is spent on destruction. After $15 \mu / \mathrm{s}$, the erosion of the projectile stops, and the rest of the energy is absorbed by the substrate [10].

The third type of waves can exist near the surface. These waves were investigated by Rayleigh [11], who showed that their action rapidly decreases with depth and their propagation speed is less than that of bulk waves. Usually, under some assumptions, the speed of the Rayleigh wave is

$$
C_{R}=0.9194 C_{\mathrm{t}} \text {, }
$$

where $C_{\mathrm{t}}$ is the speed of transverse waves. In a more general form, we can write

$$
C_{R} / C_{\mathrm{t}}=(0.87-1.12 v) /(1+v),
$$

where $v$ is Poisson's ratio.

The distribution of the excitation energy of a sound wave at the axial normal load is shown in Fig. 1 (at $v=$ $0.6)[12]$.

The issue of the maximum limiting fracture velocity has been discussed and investigated many times. All of these works can be divided into four groups, in general, reflecting four groups of solids.

Griffiths believed that crack growth begins with the speed of elastic waves.

Mott obtained the following expression for the maximum possible fracture rate of a crack with the initial length $l_{0}[13]$ :

$$
V_{\max }=\sqrt{\frac{2 \pi E}{k \rho}}\left(1-\frac{l_{0}}{l}\right)^{1 / 2}
$$

where $l$ is the final crack length.

$$
\begin{gathered}
\text { Coefficient } \sqrt{\frac{2 \pi}{K}} \text {, is about } 0.3 \text { and at } l \gg l_{0}, \\
\qquad v=0.38 \frac{C_{1}}{\rho^{\frac{1}{2}},}
\end{gathered}
$$

which is very similar to Ashby's parameter $M$.

The third group of works is based on the proposal, according to which the limiting velocity of a crack is limited by the velocity at which the branching process begins, which is approximately 0.6 times the velocity of the transverse

In the last group, the maximum crack velocity is identified with the propagation velocity of Rayleigh waves. A review of these works is presented in detail in [14]. It is known that when a pulsed load is applied, 


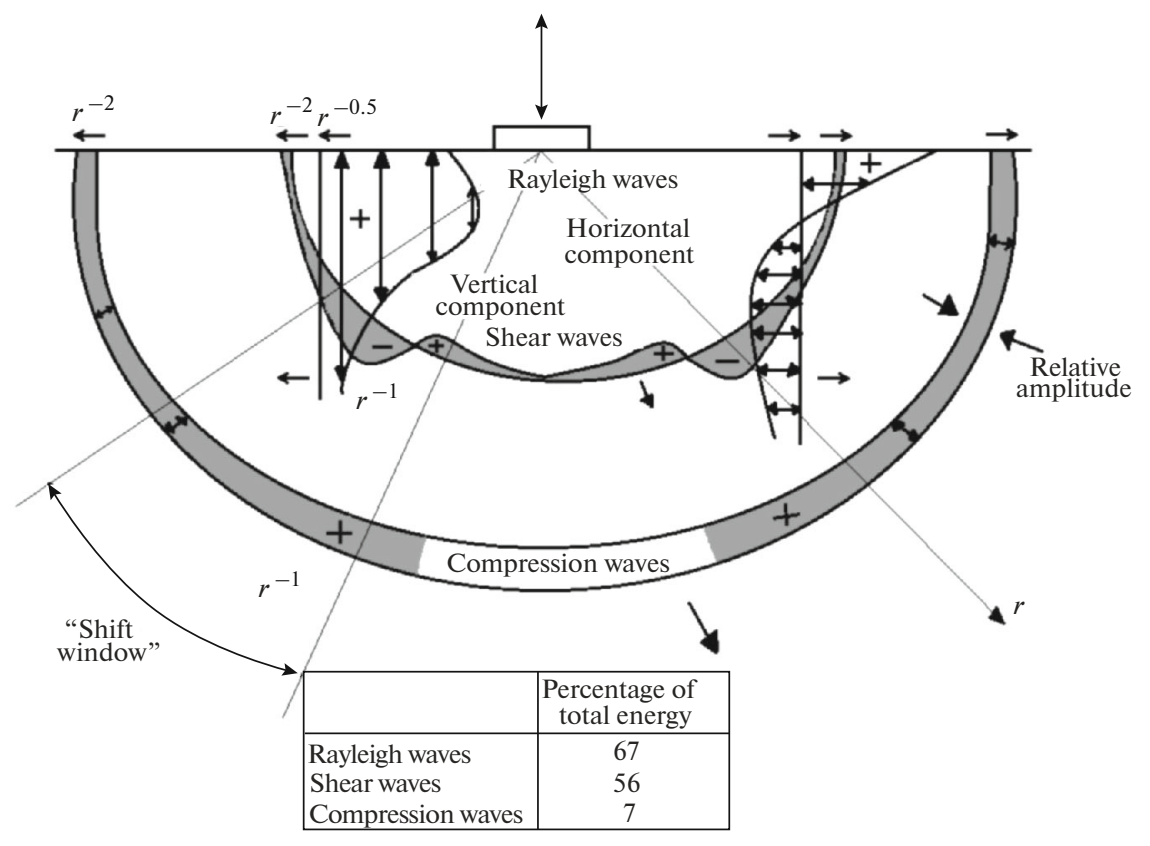

Fig. 1. Distribution of elastic waves in a solid from [10].

crack growth accelerates sharply. According to the estimates in [15],

$$
r=\sqrt{\rho C_{\mathrm{t}}^{3 / 2}}
$$

where $r$ is the radius of destruction of an ideally brittle infinite body caused by an axial impulse

$$
\rho=2 \pi r_{0} q \Delta t \text {, }
$$

where $r_{0}$ is the radius of the indenter diameter, $q$ and $\Delta t$ are the average value of the energy and time of interaction of the indenter and the obstacle, and it is assumed that the radius of destruction $r$ is much larger than the radius of the initial hole $r_{0}$.

A brittle cleavage always contains numerous steps and tongues, which are a consequence of cleavage on the cleavage plane, twin plane, and the intersection of a crack with screw dislocations. In addition, such steps can appear when a crack crosses the boundaries of subgrains and weakly misoriented crystallites. The following definition can be put forward: a fracture is brittle if the elastic energy of the destroyed body is sufficient for its flow and completion.

It is difficult to imagine the initiation of microcracks in crystalline materials bypassing the stage of plastic deformation. If plasticity is required for crack initiation, then its role is not significant during crack propagation. It is always possible to imagine the opening of a fast crack due to the elastic rupture of bonds at the mouth of the crack. The loads there are close to the theoretical strength.

A fracture can remain brittle if there is a supercritical stage of avalanche quasi-elastic crack growth, when its high propagation velocity excludes the possi- bility of using the impact energy and the only source of elastic energy for feeding the crack is the long-term decay of the stress field of the target itself after impact [14].

Inelastic deformation leads to the following stages of destruction, depending on the magnitude of the applied stress:

- An axial fracture of the target due to macroscopic cracks expanding in the direction of axial compression in the absence of any lateral loading;

- Formation of defects or macroscopic shear failure;

- Viscous flow under conditions of sufficiently large axial compression.

The transition from a brittle to ductile fracture occurs when a microscopic deformation of the target becomes more uniformly distributed in the volume [14].

Let us define viscosity as

$$
\Delta=K_{c} / \tau_{y}(\pi c)^{1 / 2}
$$

where $K_{c}$ is approximately equal to the Griffiths coefficient and $\tau_{y}$ is the shear stress. The value of $\Delta$ at room temperature for viscous materials, such as steels or aluminum, is quite large (3-4 for steels and somewhat higher for aluminum in the presence of microcracks of the order of the grain size). For crystalline bodies with microcracks, the value of $\Delta$ is quite small, on the order of a few hundredths. These materials are thus "brittle," although their brittleness or toughness will also depend on the values of the loading ratio $Z_{1}$ to the load at the mouth of crack $Z_{2}$, where $l_{0}$ is the crack's length at the beginning of the growth, $L$ is the crack's length, and the characteristic coefficient $l / l_{0}$ is less than one. 


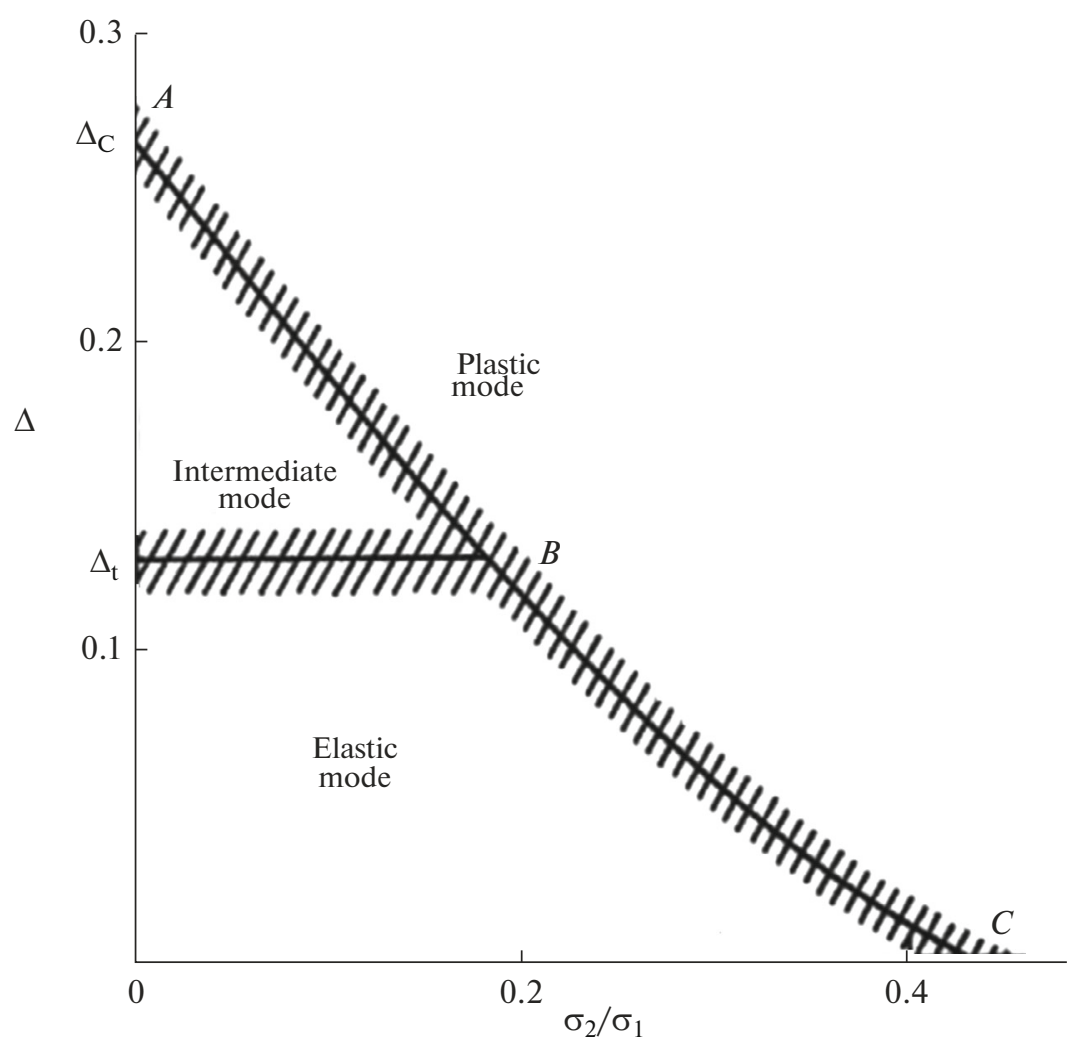

Fig. 2. The brittle-ductile transition diagram from [14].

Figure 2 shows the diagram of the brittle-ductile transition from [16].

An accurate model must describe the various inelastic processes in order to use the appropriate laws and equations. For example, a uniaxial model of splitting and defect formation under various constraints was considered in [17] and founded the development of microcracks in the deformation-stress plane. However, when moving into three-dimensional space, such an analysis is very difficult.

\section{RESULTS OF THE STUDY AND THEIR DISCUSSION}

In [14], a micromechanical model for highly deformed ceramics based on the formation of noninteracting microcracks uniformly distributed in the volume is presented.

In general, these four basic concepts can be presented as a theoretical basis for describing the inelastic fracture of ceramics.

In the first representation, the material is presented as elastic and the stresses are calculated based on Hooke's law.

In the second one, stresses are estimated that tend to zero when the variable in the equation of state reaches the critical value. The behavior of ceramics under load can be either elastic or elastic-plastic.
The third view considers ceramics as an elasticplastic medium, and uses the same conditions and equations of state as for metals.

The fourth is based on the statistical description of the number of cracks per unit volume as a function of position, crack size, and orientation with respect to the direction of the deformation.

A detailed review of these works is presented in [17].

Together with [16], these concepts, despite their obvious limitations (model), unequivocally indicate that the plastic (i.e., nonlinear relationship between the stress and strain) behavior of ceramics is a consequence of brittle grinding and is determined by the breaking of the interatomic bonds between the particles. This problem was posed and solved in [18].

A long, thin undeformed rod (projectile) (density $\rho_{c}$, length $l$, and area $S$ ), which moves along its axis at speed $v_{c}$ and meets a semi-infinite solid body (density $\rho_{n}$ ) was considered. The interaction occurs along the normal to the surface, and all the mechanical energy of the rod is spent on the dissociation (atomization) of the substance $(D)$.

In [18] it was obtained that

$$
\begin{gathered}
l_{\rho}=0.25 V_{l} \rho \sqrt{2 D / M}, \\
\varepsilon_{\rho}=l_{n} \times 2 / V_{l} \sqrt{2 D / M},
\end{gathered}
$$




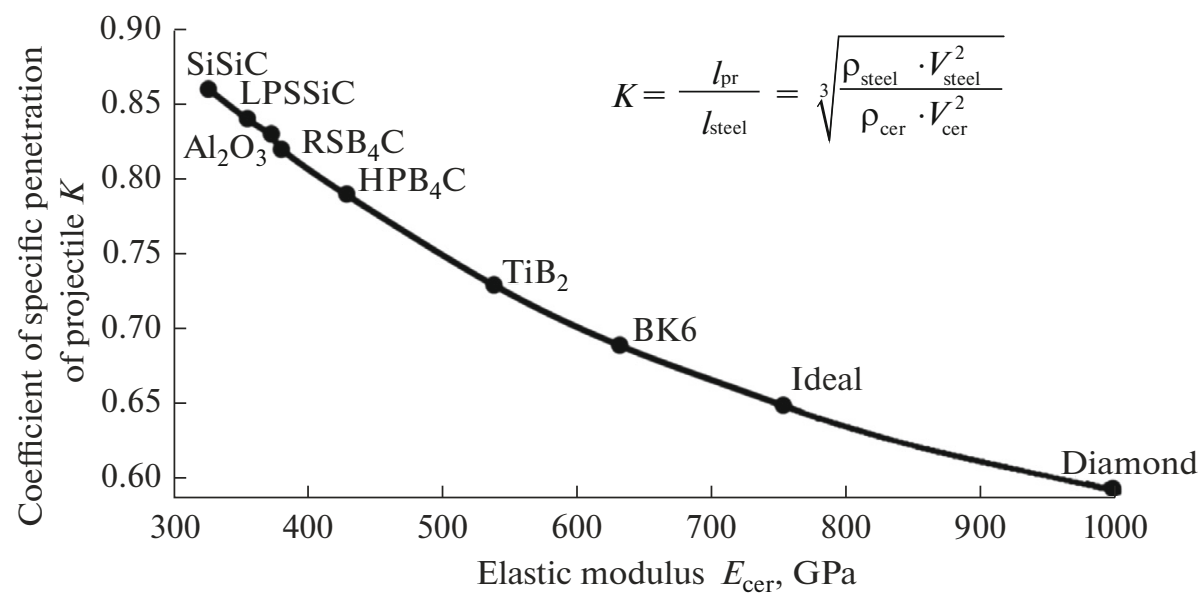

Fig. 3. Dependence of the coefficient of relative penetration of the steel striker into the ceramic.

$$
W=\frac{1}{2 \rho_{c} l S V_{c}^{2}}=D S l_{n} / V,
$$

where $W$ is the mechanical energy of the rod, $l_{n}$ is the depth of the cavity formed in the substance, $V$ is the volume of one mole of the substance, $M$ is the $\mathrm{g} / \mathrm{mol}$ of the substance, and $V_{1}$ is the longitudinal speed of sound.

Taking into account that the relative deformation $\varepsilon_{\mathrm{p}}=l_{n} / l$, we obtain the final formula of the equation

$$
l_{n}=a l_{c} \sqrt[3]{\rho_{c} V_{c}^{2} / \rho_{n} V_{l}^{2}}
$$

where $a=(\ln 2)^{2 / 3}$, and $\rho_{c}$ and $\rho_{n}$ are the density of the rod and the ceramic, respectively.

An analysis of the obtained expression shows that under mechanical dynamic loading, the dissociation energy and the speed of sound are factors that determine the dissociation energy of loading during highspeed deformation. Moreover, using these fundamental constants, it is possible to construct a number of materials according to the degree of their resistance to dynamic loading. Figure 3 shows the curve of the dependence of the ratio of the relative penetration of steel and a number of known ceramic materials used in practice (shown in Table 2).

It is interesting that the review of works in the former Soviet Union on fracture mechanics, which appeared in 1992, gave this formula and discussed it. We have included two quotes below [19]: "Soviet studies of the mechanics of penetration in ceramics reflect more advanced thinking than Western studies due to the difference in their conceptual approaches. The

Table 2. Properties of ceramic materials

\begin{tabular}{l|c|c|c|c}
\hline \multicolumn{1}{c|}{ Material } & Density $\rho_{\text {cer }}, \mathrm{kg} / \mathrm{m}^{3}$ & Sound speed $V_{\text {cer }}, \mathrm{m} / \mathrm{s}$ & Elastic modulus $E_{\text {cer }}, \mathrm{GPa}$ & $K=l_{\text {cer }} / l_{\text {steel }}$ \\
\hline $\mathrm{Al}_{2} \mathrm{O}_{3}$ & 3750 & 9800 & 375 & 0.83 \\
$\mathrm{SiSiC}$ & 3100 & 10300 & 329 & 0.86 \\
$\mathrm{LPSSiC}$ & 3250 & 10500 & 358 & 0.84 \\
$\mathrm{RSB}_{4} \mathrm{C}$ & 2550 & 13000 & 383 & 0.82 \\
$\mathrm{HPB}_{4} \mathrm{C}$ & 2750 & 11800 & 431 & 0.79 \\
$\mathrm{BK}$ & 15000 & 6500 & 633 & 0.69 \\
$\mathrm{TiB}_{2}$ & 4500 & 11000 & 540 & 0.73 \\
$\mathrm{Ideal}_{\text {Diamond }}$ & 3350 & 15000 & 754 & 0.65 \\
Steel & 3510 & 17000 & 1000 & 0.59 \\
\hline
\end{tabular}

$\mathrm{Al}_{2} \mathrm{O}_{3}$, sintered corundum; $\mathrm{SiSiC}$, reaction sintered silicon carbide; LPSSiC, liquid phase sintered silicon carbide; $\mathrm{RSB}_{4} \mathrm{C}$, reaction sintered boron carbide; $\mathrm{HPB}_{4} \mathrm{C}$, hot pressed boron carbide; $\mathrm{BK} 6$ alloy $\mathrm{WC}+6 \% \mathrm{Co}$; $\mathrm{TiB}_{2}$ sintered titanium diboride; Ideal, material of diamond-silicon carbide; Diamond, single-crystal diamond. 

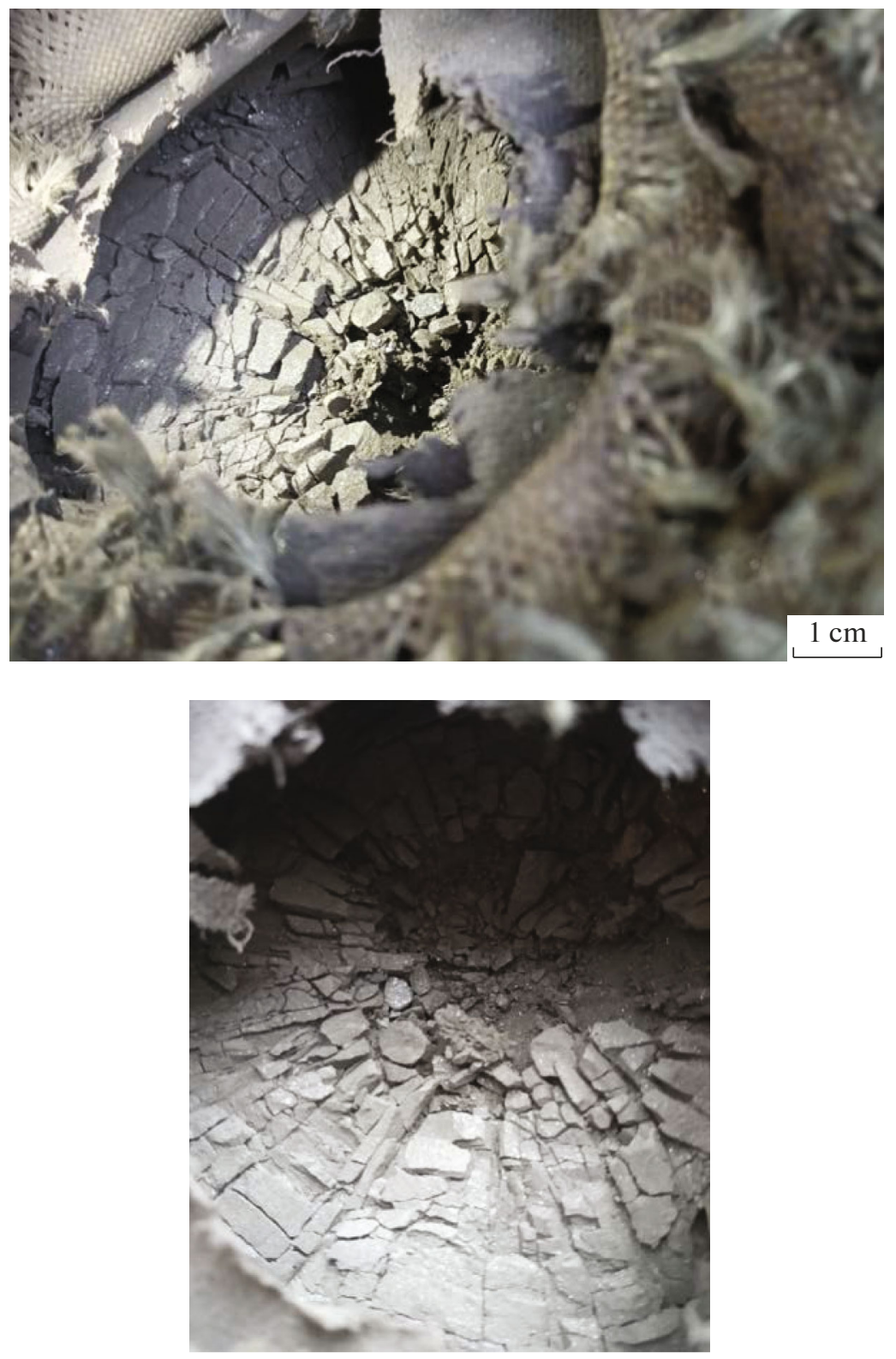

Fig. 4. Destruction of "Ideal" ceramics.

development of the concept of characteristic waves of failure refers (probably) to tensile failure and precedes crater formation ... The Soviet experimental data confirm this hypothesis." We have also included another important quote [19]: "Soviet publications of analytical and experimental work were more advanced than those in the West by several years."

In conclusion, we present a photograph of the fracture's cavity of the "Ideal" ceramics (Fig. 4) under the action of an indenter $12.7 \mathrm{~mm}$ in diameter at a speed of $840 \mathrm{~m} / \mathrm{s}$. The circular and radial cracks are clearly visible. It is curious that the cavity's volume of the obstacle is about $20 \%$ of the total volume of the object, which is in good agreement with [2].

\section{CONFLICT OF INTEREST}

The authors declare that they have no conflict of interest.

\section{OPEN ACCESS}

This article is licensed under a Creative Commons Attribution 4.0 International License, which permits use, sharing, adaptation, distribution and reproduction in any medium or format, as long as you give appropriate credit to the original author(s) and the source, provide a link to the Creative Commons licence, and indicate if changes were made. The images or other third party material in this article are included in the article's Creative Commons licence, unless indicated otherwise in a credit line to the material. If material is not included in the article's Creative Commons 
licence and your intended use is not permitted by statutory regulation or exceeds the permitted use, you will need to obtain permission directly from the copyright holder. To view a copy of this licence, visit http://creativecommons.org/licenses/by/4.0/.

\section{REFERENCES}

1. Ashby, M.F. and Cebon, D., Materials selection in mechanical design, J. Phys. IV, 1993, vol. 3, no. C7, pp. 1-9.

2. Crouch, J.G., Introduction to armor materials, Sci. Armor Mater., 2017, vol. 1, p. 33.

3. Kocer, C., Using the Herieah fracture system to measure crack growth data; review, Int. J. Fract., 2003, vol. 121, no. 3, pp. 111-132.

4. Shevchenko, V.Ya., Vvedenie v tekhnicheskuyu keramiku (Introduction to Technical Ceramics), Moscow: Nauka, 1993.

5. Brandon, D.G., Armor. Concise Encyclopedia of Advanced Ceramic Materials, Oxford: Pergamon, 1991, pp. 22-25.

6. Hazell, P.J., Armor, Materials, Theory, Design, Boca Raton, FL: CRC, 2016, p. 231.

7. McCauley, J., An introduction to materials by design including a dynamic stress environment, in Engineering Ceramics: Current Status and Future Prospects, 1st ed., Ohji, T. and Singh, M., New York: Wiley, 2016.

8. Woodward, R., A simple one-dimension approach to modeling ceramic composite armor defeat, Int. J. Impact. Eng., 1990, vol. 9, no. 4, p. 455.

9. Rhee, Y.W., Kim, H-W., Deng, Y., and Lawn, B.R., Brittle fracture versus quasi plasticity in ceramics: A simple predictive index, J. Am. Ceram. Soc., 2001, vol. 84 , pp. $561-565$.
10. Wilkins, M.L., Cline, C.F., and Honodel, C.F., 4th Progress Report of Light Armor Program, No. UCRL50694, Livermore: Lawrence Radiat. Lab., California Univ., 1969.

11. Raileigh, W.S., On waves propagation along the plate surface of an elastic solid, Proc. London Math. Soc., 1887, vol. 17, pp. 4-11.

12. Woods, R.D., Screening of surface waves in solids, $J$. Soil Mech. Founds Div. Am. Soc. Civ. Eng., 1968, vol. 94, pp. 951-980.

13. Mott, N.F., A theory of the origin of fatigue cracks, Acta Metall., 1958, vol. 6, no. 3, pp. 195-197.

14. Finkel', V.M., Fizika razrusheniya. Rost treshchin v tverdykh telakh (Physics of Destruction. Crack Growth in Solids), Moscow: Metallurgiya, 1970.

15. Cherepanov, G.P., On the influence of impulses on the development of initial cracks, Prikl. Mekh. Tekh. Fiz., 1963, no. 1, pp. 97-103.

16. Horii, H. and Nemat-Nasser, S., Brittle failure in composition splitting, fanlting and brittle - ductile transition, Phil. Trans. R. Soc. London, Ser. A, 1986, vol. 319, pp. 337-374.

17. Rajendran, A.M., Historical perspective on ceramic materials damage models, in Proceedings of the Ceramic Armor by Design Symposium, Ceram. Transl., 2001, vol. 134, pp. 281-308.

18. Shevchenko, V.Ya., Izotov, A.D., Lazarev, V.B., and Zhavoronkov, N.M., Dissociation energy and ultimate elastic deformation in the model of two-particle interaction, Neorg. Mater., 1984, vol. 20, no. 6, pp. 10471052.

19. Isbell, W.M., Anderson, C.E., Asay, J.R., Bless, S.J., and Grady, D.E., Penetration Mechanics Research in the Former Soviet Union, San Diego CA: Science Appl. Int., 1992. 